\title{
SISTEMAS MUNICIPAIS DE ENSINO EM MINAS GERAIS: O PAPEL DOS CONSELHOS MUNICIPAIS DE EDUCAÇÃO
}

\author{
Marisa Ribeiro Teixeira Duarte* \\ Rosimar de Fátima Oliveira**
}

RESUMO: Por meio de pesquisa realizada sobre a criação e a consolidação dos Conselhos Municipais de Educação (CMEs) no Estado de Minas Gerais, esse artigo demonstra que há elementos presentes nos atos normativos de criação dos CMEs mineiros que revelam imprecisões quanto à definição da natureza, da função e da competência de tais conselhos. Tais imprecisões contribuem para indefinições sobre a atuação desses órgãos no que se refere à gestão colegiada das políticas educacionais municipais. Ao não estabelecer regras claras para a constituição dos CMEs, remetendo para a arena política a afirmação da sua natureza, o executivo municipal formaliza juridicamente a sua existência mas pode esvaziar as suas possibilidades reais de atuação. Acrescenta-se ainda que os dados consultados revelaram, por diversas vezes, contradição entre as competências (in)definidas, as funções e a natureza atribuídas aos CMEs.

Palavras-chave: Conselho Municipal de Educação; Sistema Municipal de Ensino; Participação Social.

\footnotetext{
*Doutora em Educação pela Universidade Federal Fluminense (UFF); Professora da Universidade Federal de Minas Gerais (UFMG) e Coordenadora do Grupo de Pesquisa de Política e Administração de Sistemas de Ensino (PASE/UFMG). E-mail: mmduarte@ufmg.br

* * Doutora em Educação pela Universidade de São Paulo (USP); Professora da Universidade Federal de Minas Gerais (UFMG) e Diretora da Associação Nacional de Política e Administração da Educação (ANPAE/MG). E-mail: rosimar@ufmg.br
} 


\section{MUNICIPAL SYSTEMS OF EDUCATION IN MINAS GERAIS: THE ROLE OF THE LOCAL BOARDS OF EDUCATION}

ABSTRACT: Through research on the creation and consolidation of the Local Boards of Education (CMEs) in the State of Minas Gerais, this article intends to show that the vagueness of normative acts to create CMEs in the State of Minas Gerais contributes to uncertainties about the performance of these bodies regarding the collegial management of municipal education policies. By failing to establish clear rules for the formation of CMEs, referring the assertion of their nature to the political arena, the municipal executive power legally formalizes their existence, but can undermine their real possibilities of action. Moreover, the data have revealed, on several occasions, that there is contradiction between the (un)defined powers, the functions and the nature assigned to the CMEs.

Keywords: Local Board of Education; Municipal System of Education; Social Participation.

\section{INTRODUÇ̃̃̃o}

No Brasil, os municípios constituem entes da federação com autonomia político- administrativa e podem organizar sistemas próprios de ensino. Ou seja, no âmbito das competências estabelecidas pela Constituição Federal (CF) de 1988 (BRASIL, 1988), cabe ao poder público municipal a administração de seu sistema de ensino. Além das atribuições de oferta e atendimento previstas na Constituição, a Lei de Diretrizes e Bases da Educação Nacional de 1996 (LDB) - n. 9.394, de 20 de dezembro de 1996 (BRASIL, 1996) - faculta aos sistemas municipais a formulação de normas de gestão democrática (art. $3^{\circ}$, VIII) e de autorização, funcionamento e critérios de avaliação das instituições privadas integrantes do sistema (art. $7^{\circ}$ ), formas de ingresso e de progressão dos alunos (art. 24, II e IV) (ABREU, 2002).

Os municípios podem, observadas as determinações constitucionais, regulamentar as relações de trabalho dos profissionais e trabalhadores da educação de sua rede, definir critérios para processos seletivos de ingresso em função ou cargo público, estabelecer normas arquitetônicas para a construção de prédios escolares ou seleção de equipamentos educacionais, elaborar e implementar programas educacionais próprios e, sem ferir as diretrizes curriculares nacionais, estabelecer projeto político-pedagógico para as instituições componentes do seu sistema de ensino. Essas, dentre outras, são dimensões da administração educacional que pertencem ao âmbito decisório das autoridades públicas municipais. 
Os municípios brasileiros detêm, ainda, competências próprias de arrecadação tributária, mas estão obrigados a aplicar o percentual de $25 \%$ de sua receita de impostos e transferências na Manutenção e Desenvolvimento do Ensino (MDE) (BRASIL, 1988, art. 211). Isso significa que a destinação dos recursos vinculados à MDE é definição do poder público municipal, que é responsável por observar medidas redistributivas em relação às suas escolas (BRASIL, 1996, art. 11, II).

Por outro lado, a LDB de 1996 faculta aos municípios brasileiros se integrarem ao sistema de ensino do estado subnacional onde se encontram. Nesse caso, as autoridades públicas locais devem observar, além das normas nacionais afetas a todos os sistemas de ensino, aquelas aprovadas no âmbito estadual e relacionadas à organização e funcionamento da educação básica. Mas localidades sem sistema próprio de ensino detêm a autonomia administrativa prevista na CF de 1988, ou seja, no campo educacional elaboram planos de carreira de seus profissionais, definem critérios para pagamento, reforma e construção de escolas etc. A Lei n. 9.131, de 24 de novembro de 1995 (BRASIL, 1995) autoriza, ainda, o Conselho Nacional de Educação (CNE) a elaborar resoluções e emitir pareceres sobre questões que abranjam mais de um nível ou modalidade de ensino e relativas à aplicação da legislação educacional no que diz respeito à integração entre os diferentes níveis e modalidades. Sob essa competência, o CNE elaborou, a partir do ano de 2000, as diretrizes operacionais relacionadas à administração da educação infantil, planos de carreira dos profissionais e trabalhadores em educação, funcionamento da educação de jovens e adultos, dentre outras.

Desse modo, a convivência de competências específicas e concorrentes configura um sistema público de educação básica no Brasil, onde a norma constitucional que orienta quanto ao regime de colaboração entre os entes federados acha-se em tradução institucional. $\mathrm{Na}$ atualidade, a repartição de competências e o regime de colaboração vêm efetivando-se com suporte na articulação dos procedimentos de avaliação e de financiamento. Trata-se do modo de regulação por desempenho (MAROY, 2008), onde as relações federativas e intrassistêmicas são valoradas de acordo com o resultado obtido. É sob essa lógica que campos de competências e um regime de colaboração articulado normativamente e por diversos projetos centrados em resultados vêm-se construindo.

A centralidade dos Conselhos Municipais de Educação (CMEs) nesse processo é irrefutável. Desde a criação da União Nacional dos 
Dirigentes Municipais (Undime), em 1986, a demanda por maior autonomia na gestão da educação municipal foi fortemente emparelhada ao argumento da participação, como meio de legitimação dessa demanda por ampliação do poder local em relação à educação. $O$ fato de os conselhos de educação, no período anterior à LDB de 1996, estarem atrelados a um ato autorizativo dos conselhos estaduais de educação, conforme previa a Lei n. 5.692/1971 (BRASIL, 1971), excluía a autonomia como meio de atuação possível.

No caso de Minas Gerais, mesmo após a promulgação da LDB de 1996, o Conselho Estadual de Educação (CEE/MG) emitiu o Parecer n. 500, de 13 de maio de 1998, estabelecendo orientações para a organização e a constituição dos sistemas municipais de ensino e de CMEs no estado (MINAS GERAIS, 1998).

Segundo o Parecer n. 500/1998, os municípios mineiros, diante do disposto na LDB de 1996, além de escolher entre constituir seu sistema municipal de ensino ou se integrar ao sistema estadual, poderiam também optar por uma terceira alternativa, que seria a de "[...] compor com o estado um Sistema Único de Educação Básica” (MINAS GERAIS, 1998, p. 5). Reconhecendo essa alternativa como avançada para o modelo jurídico daquele momento, o parecer destaca a potencialidade dessa alternativa para substituir a organização administrativa das escolas - estaduais e municipais - por outra forma de organização, tornando-as unicamente escolas públicas. Afirma o parecer:

[...] o sistema único de educação básica consiste em uma relação entre Estado e Municípios que se caracteriza por estar além do regime de colaboração ou do sistema de integração Estado-Município. O sistema único não se limita à existência de normas educacionais comuns [...] nem mesmo se confunde com uma repartição de responsabilidades e encargos entre Estado e Município. O sistema único consiste na adoção de normas educacionais comuns, podendo, inclusive, chegar à manutenção e administração compartilhada da rede de escolas, que deixariam de ser apenas estaduais ou municipais e passariam a ser escolas públicas, de responsabilidade simultânea do Estado e Município. A instalação de um Sistema Único de Educação Básica fundamenta-se no estabelecimento de princípios e valores comuns, bem como indicadores de qualidade que a comunidade pretenda que orientem a educação básica a todos cidadãos dos município nas escolas localizadas em seu território, quer sejam públicas ou privadas, bem como outras formas de educação existentes [...] (MINAS GERAIS, 1998, p. 7, destaque nosso). 
A proposta de um sistema único, ainda conforme o Parecer n. 500/1998, poderia integrar um conjunto de municípios ou uma região por meio de normas estabelecidas por um Conselho Regional de Educação Básica, formado pelos municípios partícipes do sistema e pelo Estado de Minas Gerais.

Os CMEs, entretanto, ainda segundo o Parecer n. 500/1998, deveriam ser criados independentemente da forma de organização da educação existente em cada município. Naqueles em que o sistema próprio não estivesse constituído, tais conselhos serviriam para consolidar a educação local e, futuramente, tornar autônomo o seu sistema de ensino. O parecer inclui recomendações para a criação dos CMEs, sugerindo aos municípios sua constituição e referindo-se genericamente às suas atribuições (MINAS GERAIS, 1998).

A literatura disponível sobre a atuação dos CMEs no Estado de Minas Gerais (ALMEIDA, 2006; ALVES, 2005; AMORIM, 2005; LIMA; NUNES, 2011; SARMENTO, 2005; SILVEIRA JUNIOR, 2009; TEIXEIRA, 2004; TELES, 2003), preponderantemente teses e dissertações, à semelhança da literatura sobre outros estados, é centrada em estudos de caso e discute a atuação dos CMEs com foco no tema da participação dos atores, atribuindo papel secundário à associação entre o desenho institucional (organizacional e de funcionamento) e sua capacidade deliberativa ${ }^{2}$. Subjaz nesses autores a defesa de funções propositivas como característica de uma participação mais democrática dos interesses de diversos segmentos e grupos sociais, denominando como tradicionais as funções normativas e deliberativas.

Neste artigo, com a finalidade de compreender o papel exercido pelos CMEs na constituição dos sistemas municipais de ensino de Minas Gerais ${ }^{3}$, analisou-se a base de dados da pesquisa Perfil dos Municípios Brasileiros (INSTITUTO BRASILEIRO DE GEOGRAFIA E ESTATÍSTICA, 2009) e, comparativamente aos dados disponíveis nessa base, foram abordados os dados disponíveis sobre o Sistema de Informações dos Conselhos Municipais de Educação (SICME) (BRASIL, 2008). A base de dados da pesquisa Perfil dos Municípios Brasileiros foi analisada por meio de estatística descritiva com a finalidade de identificar a existência de CMEs nos municípios mineiros, por ano, bem como identificar a natureza institucional deles através da sua constituição, referida na base de dados do IBGE como consultiva, deliberativa, normativa, fiscalizadora e paritária. A base de dados SICME também foi 
analisada por meio de estatística descritiva, com o objetivo de ampliar o escopo analítico permitido pelas variáveis disponíveis na base de dados do IBGE. Assim, acrescentaram-se à natureza institucional mencionada acima os dados relativos às funções propositiva e mobilizadora, disponíveis nessa base SICME e ausentes na base do IBGE. Além disso, realizou-se ainda análise bivariada dos dados disponíveis sobre a criação dos CMEs e a constituição dos sistemas municipais de ensino nos municípios mineiros a fim de compreender a evolução da função normativa atribuída aos mesmos.

Realizou-se, ainda, além da abordagem descritiva dos dados disponíveis nas bases mencionadas acima, análise de conteúdo dos atos normativos de criação de CMEs em 158 municípios mineiros. Procedeu-se a análise de conteúdo por categorização a fim de compreender, por meio das categorias natureza, função e competência, o sentido atribuído aos CMEs mineiros por seus atos normativos de criação. Os dados analisados mostram que há uma indefinição significativa quanto ao papel dos CMEs no âmbito dos sistemas municipais de ensino mineiros. Além disso, o movimento de criação e consolidação dos CMEs no Estado de Minas Gerais, apesar da expansão quantitativa pós-LDB, tem se revelado heterogêneo, instável e frágil.

\section{A CONSTITUIÇÃO DE CMES EM MINAS GERAIS}

Em Minas Gerais, a participação dos 853 municípios na matrícula da educação básica é inferior à participação do governo estadual (Figura 1). Esse dado é expressivo da multiplicidade de pequenas redes municipais de educação existentes no estado. No entanto, as dimensões assumidas por esse conjunto são significativas e é sobre esse cenário que se multiplicou a criação dos CMEs.

Segundo a base de dados da pesquisa Perfil dos Municípios Brasileiros (INSTITUTO BRASILEIRO DE GEOGRAFIA E ESTATÍSTICA, 2009), 657 (77\%) municípios do Estado de Minas Gerais possuíam CMEs no ano de 2009. Desse total, apenas 90 (14\%) foram criados antes da promulgação da LDB de 1996 (BRASIL, 1996), correspondendo, portanto, a uma estrutura anterior à possibilidade jurídica de instituição de sistemas municipais de ensino autônomos. Influenciados pela promulgação daquela lei, em 1997 foram criados nos municípios mineiros 234 (36\%) CMEs, tendência que 


\section{Figura 1}

Distribuição de matrículas na educação básica por dependência administrativa: Brasil e o Estado de Minas Gerais - 2010.

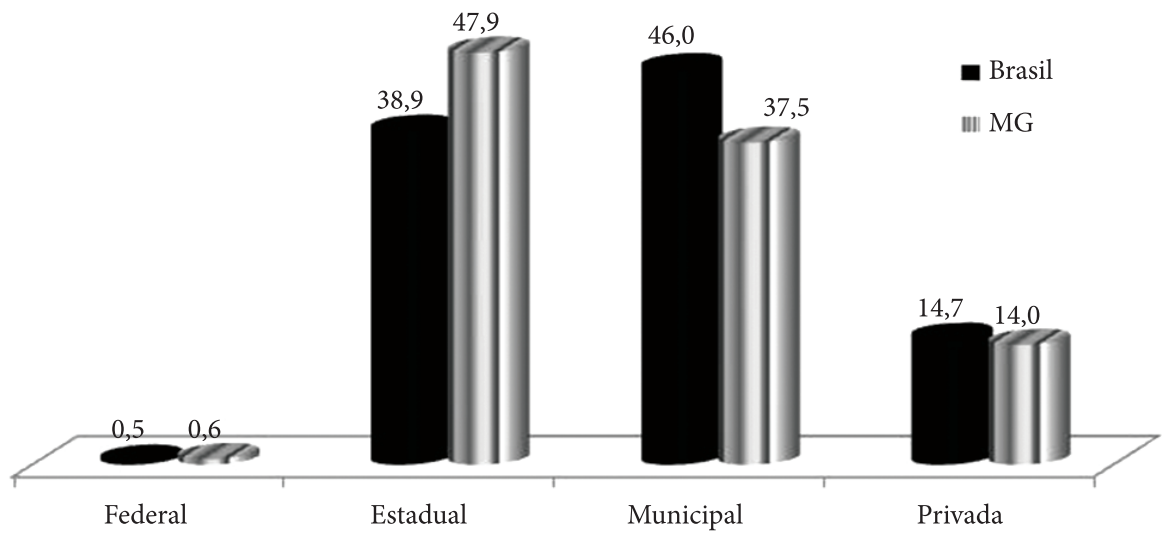

Fonte: Brasil. MEC. INEP (INSTITUTO NACIONAL DE ESTUDOS E PESQUISAS EDUCACIONAIS, 2011). Nota: Elaboração das autoras.

se seguiu nos anos subsequentes, quando, somente entre 1997 e 1999, 346 (53\%) CMEs foram criados no estado (Figura 2).

No Estado de Minas Gerais, como no Brasil (INSTITUTO BRASILEIRO DE GEOGRAFIA E ESTATÍSTICA, 2009), o ato de criação informa a multiplicação de CMEs no período onde se achavam em pauta proposições, sob a égide do Ministério da Administração e Reforma do Estado, de disseminação de modelos pós-burocráticos de administração (ABRUCIO, 1998). O diagnóstico difundido no período pelo ministério considerava a existência de uma excessiva hierarquização e falta de contato entre a burocracia e a comunidade. Em paralelo, movimentos sociais os mais diversos propugnavam por maior participação na formulação das políticas educacionais.

A pesquisa Perfil dos Municípios Brasileiros (INSTITUTO BRASILEIRO DE GEOGRAFIA E ESTATÍSTICA, 2009) também informa quanto à natureza institucional, denominada caráter, dos CMEs. O levantamento permite identificar se os conselhos possuem ou não função consultiva, deliberativa, normativa e fiscalizadora. Além disso, é possível saber, quanto à composição, os conselhos que se identificam como paritários e aqueles que não se identificam como tal. 
Figura 2

CMEs por ano de criação em Minas Gerais - 1969-2009.

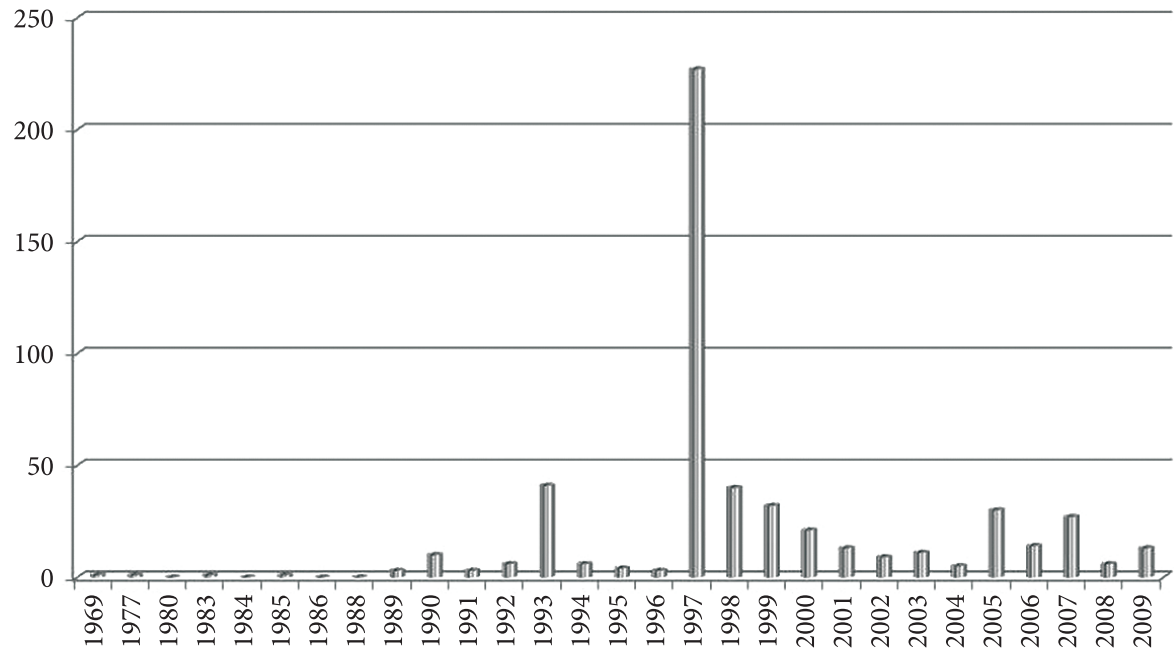

Fonte: IBGE (INSTITUTO BRASILEIRO DE GEOGRAFIA E ESTATÍSTICA, 2009).

Nota: Elaboração das autoras.

Observa-se que a função normativa é a menos presente entre os conselhos mineiros, comparada às demais funções. Enquanto $83 \%(n=547)$ dos municípios afirmaram na pesquisa sobre o seu perfil (INSTITUTO BRASILEIRO DE GEOGRAFIA E ESTATÍSTICA, 2009) que possuem CMEs com caráter consultivo, apenas 54\% $(\mathrm{n}=358)$ dos conselhos afirmaram possuir caráter normativo (Figura 3). Do mesmo modo, há uma menor proporção de municípios com CMEs com função de fiscalização.

A hipótese de que as funções normativa e fiscalizadora poderiam resultar de um aprofundamento das práticas de participação e da influência da gestão democrática da educação prevista na CF de 1988 e ratificada em legislação posterior, não pode ser confirmada pelos dados de criação de CMEs com tais funções em Minas Gerais. Diferentemente do que se poderia presumir a partir dessa hipótese, a criação de CMEs sem função normativa e fiscalizadora não se reduz ao longo dos anos, nem a partir do marco de criação da LDB de 1996. Dos 299 municípios que criaram CME em Minas Gerais sem a função normativa, segundo a pesquisa do IBGE (INSTITUTO BRASILEIRO DE GEOGRAFIA E ESTATÍSTICA, 2009), 87\% ( $\mathrm{n}=261$ ) o fizeram após a promulgação da LDB de 1996 (Figura 4). 
A atribuição da função normativa não parece estar, desse modo, direta e positivamente associada à hipótese de empoderamento dos CMEs vis-à-vis à formalização da gestão democrática da educação nos municípios mineiros. De outro modo, o menor percentual de institucionalização dessa

Figura 3

CMEs por função e composição em Minas Gerais - 2009.

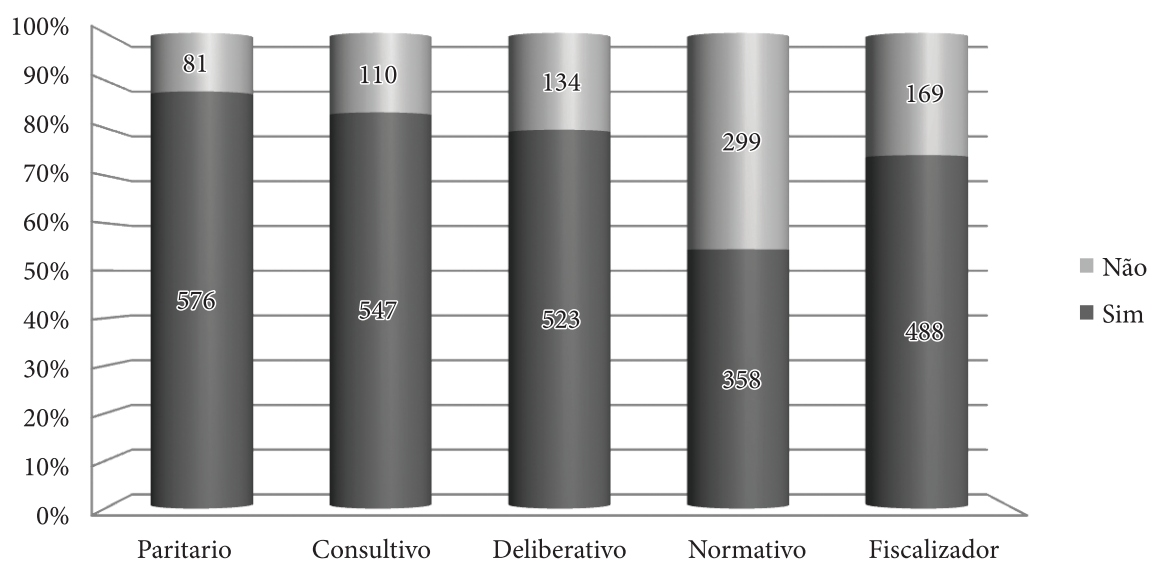

Fonte: IBGE (INSTITUTO BRASILEIRO DE GEOGRAFIA E ESTATíSTICA, 2009).

Nota: Elaboração das autoras.

Figura 4

CMEs sem função normativa, por ano de criação, em Minas Gerais - 1998-2009.

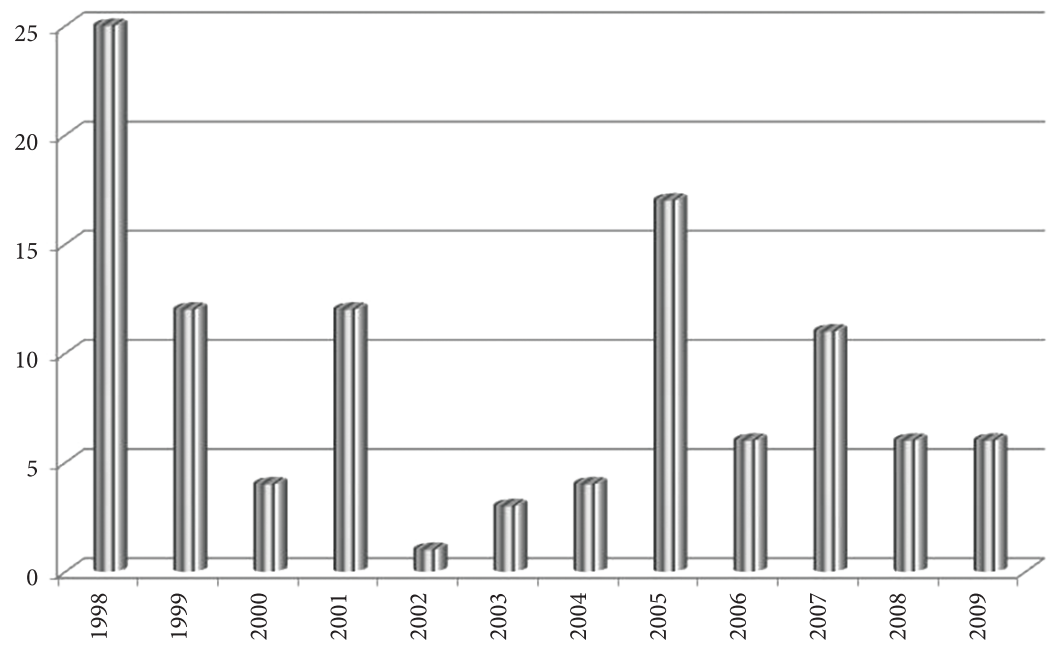

Fonte: IBGE (INSTITUTO BRASILEIRO DE GEOGRAFIA E ESTATíSTICA, 2009).

Nota: Elaboração das autoras. 
função na criação dos CMEs mineiros pode estar relacionado à opção pela adesão ao sistema estadual de educação e a consequente atribuição da função normativa aos respectivos órgãos estaduais.

Quanto à função fiscalizadora, dos 169 municípios que criaram conselhos sem essa função, 82\% ( $\mathrm{n}=139)$ o fizeram entre os anos de 1997 e 2009. Esse dado evidencia que, para o conjunto dos conselhos sem função fiscalizadora nos municípios mineiros, a LDB de 1996 (BRASIL, 1996) não induziu uma reversão dessa tendência funcional, embora tenha induzido o crescimento do número de conselhos, como já demonstrado.

A situação dos CMEs no Estado de Minas Gerais também pode ser analisada a partir do Sistema de Informações dos Conselhos Municipais de Educação (SICME), ferramenta de acesso restrito para a coleta de informações sobre os CMEs, cuja base de dados é alimentada pelos presidentes dos conselhos e secretários municipais de educação (BRASIL, 2008). A compilação dos dados de 2004 a 2007, publicada em 2008 pelo MEC, informa sobre a existência dos conselhos a partir da instituição do ato legal de criação dos mesmos, metodologia diferente da pesquisa Perfil dos Municípios (INSTITUTO BRASILEIRO DE GEOGRAFIA E ESTATÍSTICA, 2009), cuja informação deriva do instrumento de coleta do IBGE aplicado aos gestores dos municípios. O SICME informa a existência de 501 CMEs com ato legal de criação cadastrados na sua base de dados entre os anos de 2004 e 2007 no Estado de Minas Gerais. Se, para efeito comparativo, limitarmos a análise do banco de dados da Pesquisa Munic2009 ao ano de 2007 (INSTITUTO BRASILEIRO DE GEOGRAFIA E ESTATÍSTICA, 2009), identificamos, até este ano, a criação de 627 CMEs. Há, portanto, uma evidente inconsistência entre os resultados obtidos, uma vez que a base do IBGE informa a existência de 126 conselhos a mais que a base de dados do MEC, uma diferença significativa de $24 \%$.

A diferença pode estar relacionada à metodologia utilizada que, no caso do SICME, considerou a existência do ato legal de criação do conselho municipal de educação informada pelo responsável. E, no caso do IBGE (INSTITUTO BRASILEIRO DE GEOGRAFIA E ESTATÍSTICA, 2009), considerou a informação prestada pelo gestor no instrumento de coleta adotado pela pesquisa, que sofre conferência por amostragem. Além disso, sabendo-se que o cadastro na base SICME é um ato voluntário, é 
preciso considerar a existência de municípios com ato legal de criação não cadastrados naquele sistema.

O valor agregado pela fonte do SICME na análise dos CMEs de Minas Gerais, entretanto, está nas informações que acrescenta quanto à composição dos conselhos e as funções mobilizadora e propositiva não incluídas na Pesquisa Munic-2009 (INSTITUTO BRASILEIRO DE GEOGRAFIA E ESTATÍSTICA, 2009). Além disso, é significativo observar que, embora sejam identificados na base SICME 59\% $(n=501)$ dos municípios mineiros com ato legal de criação do CME, no mesmo período somente $64 \%(n=322)$ desses haviam constituído sistemas municipais de ensino próprios.

Dito de outro modo, observamos que a criação de mais de um terço dos CMEs mineiros cadastrados na base SICME não está relacionada à opção do município pela constituição de sistema de ensino próprio, o que pode significar a afirmação da hipótese de que aderiram ao sistema estadual de ensino. Essa hipótese corrobora o sentido atribuído acima ao baixo percentual verificado de conselhos com função normativa.

Além de se referir às funções consultiva, deliberativa e normativa dos conselhos, cujos resultados são discretamente inferiores aos resultados auferidos pela pesquisa do Perfil dos Municípios (INSTITUTO BRASILEIRO DE GEOGRAFIA E ESTATÍSTICA, 2009), dada a natureza de cada uma das bases, como já observado, a base SICME informa ainda sobre as funções mobilizadora e propositiva, que foram identificadas, respectivamente, em $37 \%$ e 36\% dos conselhos pesquisados (Figura 5).

O acréscimo das funções propositivas e mobilizadoras na base SICME, somado ao percentual de conselhos em cujas leis de criação figuram tais funções, chama a atenção para o escopo dos documentos legislativos em cujo texto são criados os conselhos ${ }^{4}$. Através do acesso ao Sistema de Monitoramento, Execução e Controle do Ministério da Educação (SIMEC), no Módulo Plano de Ações Articuladas (PAR), é possível visualizar as leis de criação dos CMEs mineiros que preencheram o formulário eletrônico e anexaram, conforme solicitado, o referido ato, além de outros. A análise dessa legislação permitiu conhecer, através do texto normativo, uma caracterização jurídica bastante imprecisa dos CMEs no estado.

Identificamos na base de dados SIMEC-PAR um total de 158 municípios com ato de criação do respectivo CME anexado ao formulário 
Figura 5

CMEs por função, em Minas Gerais, segundo as bases SICME e IBGE - 2008 e 2009.

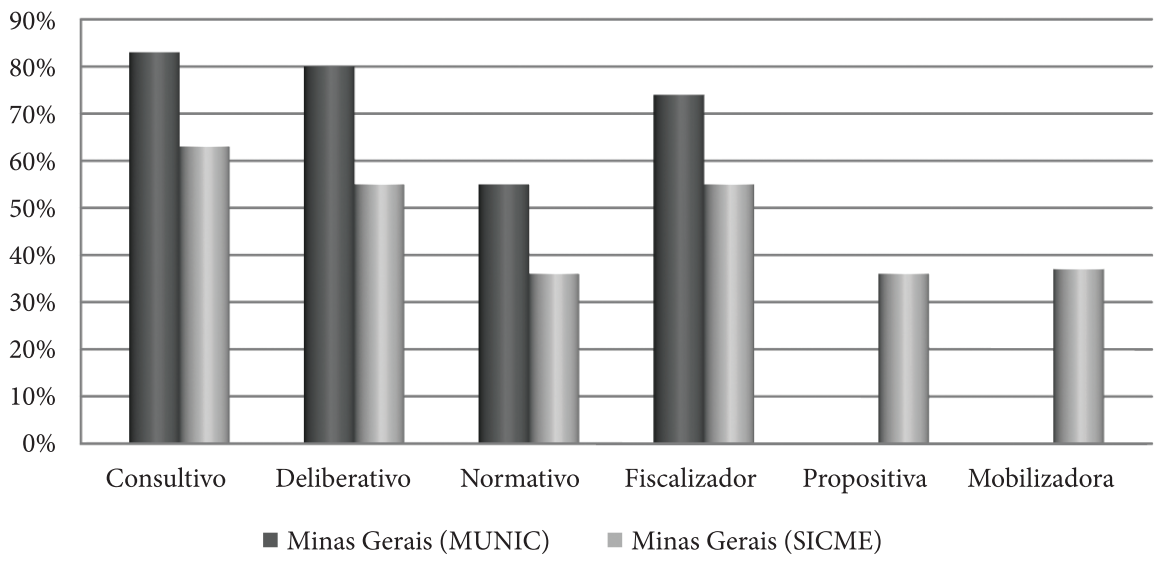

Fonte: IBGE (INSTITUTO BRASILEIRO DE GEOGRAFIA E ESTATíSTICA, 2009) e Brasil (2008).

Nota: Elaboração das autoras.

eletrônico do sistema. A leitura desses documentos, entretanto, não permitiu identificar objetivamente as funções atribuídas aos conselhos, na sua maioria. Não há, nas leis analisadas, definição clara da natureza, função e competência dos conselhos, muitos sendo identificados a partir de uma lista de tarefas que se referem mais aos seus aspectos procedimentais, compreendidos nas suas competências ou atribuições, do que propriamente à sua constituição política. Assim, afirmamos como Werle (2008, p. 212) que o texto legal revela "[...] materialidade que contém decisões políticas prévias e que, por seu conteúdo, possibilitam rearticulações do sistema político-administrativo, da estrutura institucional da educação e dos processos políticos locais a ela relacionados."

\section{FUNÇÕES E COMPETÊNCIAS DOS CMES MINEIROS}

Diferentemente do que ocorre na área da saúde, por exemplo, a legislação educacional de âmbito federal não obriga a criação dos CMEs. A razão dessa liberdade jurídica está no amplo reconhecimento formal da autonomia política e administrativa dos municípios, garantida pelo modelo federativo que, no caso da educação, acrescenta o regime de colaboração como contrapeso de uma possível competição entre os entes federados. 
O princípio da autonomia político-administrativa sobre o qual a LDB de 1996 sustenta o modelo de gestão educacional nos municípios, porém, deve ser entendido não só como a possibilidade de constituir, ou não, sistemas próprios de ensino e criar CMEs mas, também, autonomia para definir a natureza, as funções e as competências desses conselhos. Essa definição, que deve resultar de uma construção política, tem sua expressão formal no ato legislativo da criação desses conselhos (CURY, 2006). A natureza, a função e as competências dos CMEs são campos conceituais específicos e podem ser expressos no texto legislativo correspondendo a uma tipologia de círculos concêntricos (Figura 6). As competências estão contidas nas funções, as quais, por sua vez, estão contidas na natureza dos conselhos. Dessa maneira, podemos considerar que a definição das competências e das funções, as quais se estruturam sobre um mesmo eixo e se sustentam numa mesma unidade de princípios, está condicionada à natureza atribuída aos conselhos.

Embora não estejam legalmente prescritas, a natureza, a função e a competência dos CMEs vêm sendo objeto de programas de formação política ofertados pelo governo federal que corroboram uma matriz cognitiva amplamente aceita nas democracias contemporâneas, segundo a qual a

Figura 6

Modelo para análise dos atos normativos de constituição dos CMEs.

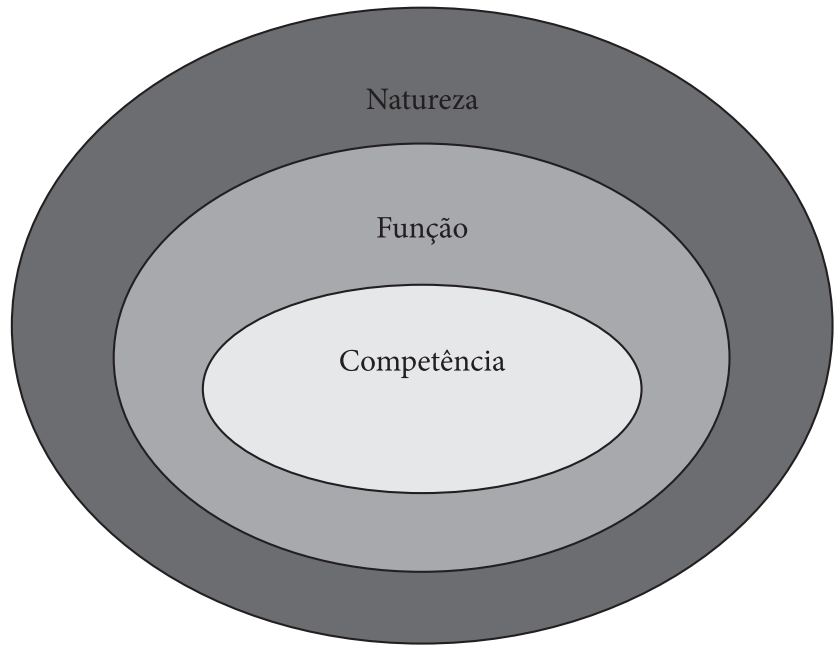

Fonte: elaboração das autoras. 
participação social constitui-se em método para efetividade das políticas ${ }^{5}$. Os materiais didáticos e instrucionais disponíveis para implementação do currículo do Programa de Capacitação de Conselheiros Municipais de Educação (PRO-CONSELHO) estimulam a criação de conselhos, ensinam como fazê-lo, orientam sobre sua estrutura e composição, induzindo, a partir da sua constituição, a criação de sistemas municipais de ensino. No documento intitulado Guia de Consulta (BRASIL, 2004), as funções dos conselhos são relacionadas às suas áreas de atuação, conforme Quadro 1.

Quanto à natureza, o documento classifica o CME como "[...] órgão colegiado de deliberação coletiva, em geral integrante ou vinculado à secretaria de educação, com relativa autonomia técnica e administrativa [...]" (BRASIL, 2004, p. 75). Essa conceituação genérica é analisada com maior profundidade por Cury (2006), que após minucioso estudo da função normativa dos Conselhos de Educação na tradição jurídico-política da educação brasileira, indica um conjunto de temas essenciais a serem submetidos ao exercício reflexivo e normativo dos conselheiros municipais de educação.

A maioria das leis de criação de CMEs disponíveis na base SIMEC-PAR não dispõe sobre a natureza do conselho, definindo principalmente a sua composição e suas atribuições. Entre aquelas leis que definem a referida natureza, encontramos diferentes formulações, que vão desde a responsabilização pela afirmação dos direitos humanos no município, até a atribuição de responsabilidade técnica pela realização do censo. Pode-se afirmar, a partir desses documentos, que, do ponto de vista

Quadro 1

Funções e áreas de atuação dos CMEs, segundo o MEC.

\begin{tabular}{c|c|c|c}
$\begin{array}{c}\text { Áreas de atuação } \\
\text { Funções }\end{array}$ & $\begin{array}{c}\text { Planejamento } \\
\text { e políticas } \\
\text { educacionais }\end{array}$ & Direito à educação & $\begin{array}{c}\text { Legislação } \\
\text { educacional }\end{array}$ \\
\hline Consultiva & $\mathrm{X}$ & $\mathrm{X}$ & $\mathrm{X}$ \\
\hline Propositiva & $\mathrm{X}$ & $\mathrm{X}$ & $\mathrm{X}$ \\
\hline Mobilizadora & $\mathrm{X}$ & $\mathrm{X}$ & $\mathrm{X}$ \\
\hline Deliberativa & & $\mathrm{X}$ & $\mathrm{X}$ \\
\hline Normativa* & & $\mathrm{X}$ & \\
\hline $\begin{array}{c}\text { Acompanhamento } \\
\text { e controle }\end{array}$ & $\mathrm{X}$ & & $\mathrm{X}$ \\
\hline Fiscalizadora* & & & \\
\hline
\end{tabular}

Fonte: Brasil (2004).

Notas: Funções atribuídas no caso de o município ter sistema de ensino próprio. 
legal, os CMEs mineiros possuem naturezas diversas, variando quanto à sua constituição como órgão de Estado. As permanências observadas nos documentos legislativos permitem identificar a natureza administrativa como uma característica mais presente, seguida da natureza autorizativa e, por fim, das naturezas representativa e de controle propriamente ditas.

As funções consultiva e deliberativa foram aquelas mais apontadas pelos documentos, $77 \%(\mathrm{n}=122)$ das leis analisadas atribuíram aos conselhos tais funções. Uma variedade de outras funções também foi identificada, além da normativa, tais como as funções opinativa, colaborativa, fiscalizadora, de controle, de assessoria, de coordenação, de integração, jurídica, política, de planejamento e mobilizadora. O significado dessas funções, entretanto, só pode ser de fato conhecido se cotejado às competências atribuídas aos conselhos nos documentos. Outras pesquisas poderão esclarecer, por exemplo, os conteúdos sobre os quais tais funcionalidades estão autorizadas a operar, respondendo futuramente, entre outros, sobre o que podem legalmente deliberar ou normatizar os CMEs mineiros a partir da sua lei de criação.

A análise realizada demonstrou que, através das competências atribuídas aos conselhos por meio do seu ato de criação, muitos parecem respaldados para assumir um excesso de tarefas administrativas, empoderados para realizar funções técnicas típicas do executivo municipal. Tal configuração, além de exigente na especialização do conselheiro, pode gerar, por um lado, efeito desmobilizador, desestimulando a participação em razão do excesso de atribuições do cargo. Por outro lado, a mesma configuração pode permitir também análises mais otimistas, reconhecendo a possibilidade operacional gerada pela norma para aprofundar a influência dos conselhos nas políticas educacionais municipais.

\section{CONCLUSÕES: DAS FUNÇÕES NORMATIVAS ÀS RELAC̣ÕES FEDERATIVAS}

Os dados apresentados evidenciam a forte influência da LDB/1996 na criação dos CMEs mineiros, embora essa lei não determine a criação deles pelos municípios. Entretanto, a maioria dos CMEs criados no período pós-LDB possui caráter consultivo, com pouco mais da metade apresentando caráter normativo, que configura a possibilidade mais efetiva de intervenção desse órgão nas políticas públicas de educação dos municípios. Além disso, os dados analisados demonstraram que não há um crescimento 
proporcional entre criação de CMEs e de sistemas municipais de ensino, o que pode explicar a baixa proporção de conselhos com função normativa, comparativamente às demais funções.

A imprecisão dos atos de criação dos CMEs em Minas Gerais contribui para indefinições sobre a atuação desses órgãos no que se refere à gestão colegiada das políticas educacionais municipais. Ao não estabelecer regras claras para a constituição dos CMEs e remetendo para a arena política a afirmação de sua natureza, o executivo municipal formaliza juridicamente a sua existência mas pode esvaziar as suas possibilidades de atuação. Acrescenta-se ainda que a legislação consultada revelou, por diversas vezes, contradição entre as competências (in)definidas, as funções e a natureza atribuídas aos CMEs.

A situação encontrada em Minas Gerais é expressão de um fenômeno que, acredita-se, se verifica também em âmbito nacional. A ausência de norma de âmbito federal que defina a natureza dos conselhos repercutiu nos municípios com o desenvolvimento de práticas as mais diversas na gestão desses órgãos colegiados. Práticas complementares às ações do poder executivo, deliberativas e/ou propositivas de novas agendas educacionais locais convivem com outras mais desmobilizadoras, que centralizam as ações e decisões seja na administração municipal seja nos grupos com maior densidade de organização e proposição.

A CF de 1988, através do artigo 31, $\$ 1^{\mathrm{o}[6]}$, atribuiu de modo inespecífico às câmaras municipais o controle externo dos conselhos. Dispositivo constitucional pouco referido nos estudos sobre controle social da educação, o âmbito de sua aplicação na área da educação não se limita aos recursos constitucionalmente vinculados à manutenção e ao desenvolvimento do ensino. A natureza dos CMEs como órgãos sob controle externo das câmaras municipais requer o desenvolvimento de competências relacionadas à análise pedagógica da legislação educacional afeta ao âmbito dos municípios (CURY, 2006). No exercício do controle externo das câmaras municipais caberia também aos CMEs opinar sobre o conteúdo e repercussões educacionais decorrentes de medidas dos legisladores.

Se nos municípios sem tradição associativa os CMEs têm muitas vezes uma realidade formal, não atendendo minimamente aos objetivos de fiscalização e controle dos serviços e aplicação dos recursos na área da educação, as possibilidades de atuação como instâncias de deliberação mais 
democráticas são reduzidas com a inexistência de competências claramente definidas de abrangência nacional. $\mathrm{Na}$ federação brasileira há tendência nas relações intergovernamentais na área da educação, especialmente para a articulação de ações entre o executivo federal e os governos subnacionais, de contratualização em torno de projetos e programas mediante a pactuação de resultados. Se as regras que foram acordadas não puderem receber análise prévia dos Conselhos Municipais de Educação, continua-se a encobrir interesses restritos de grupos e/ou corporações sob um falso discurso de participação. $\mathrm{Ou}$ seja, as novas formas de relações intergovernamentais acham-se mescladas a velhas relações de centralismo e neopatrimonialismo e os Conselhos Municipais de Educação, instâncias de controle social e fiscalização, são responsáveis por acompanhar ações sobre as quais não deliberaram. 


\section{REFERÊNCIAS}

ABREU, M. Organização da educação nacional na constituição e na LDB. Ijuí: UNIJUI, 2002. ABRUCIO, F. L. Os avanços e os dilemas do modelo pós-burocrático: a reforma da administração pública à luz da experiência internacional recente. In: PEREIRA, L. C. B. (Org.). Reforma do Estado e administração pública gerencial. Rio de Janeiro: FGV, 1998. p. 173-200. ALMEIDA, D. C. R. Conselhos municipais de saúde e educação: distintos padrões de participação política. 2006. 210 f. Dissertação (Mestrado em Ciências Política)-Instituto de Ciências Humanas e Filosofia, Universidade Federal Fluminense, Niterói, 2006.

ALVES, D. M. V. Conselho municipal de educação de Juiz de Fora: democratização, participação e autonomia. 2005. 310 f. Dissertação (Mestrado em Educação)-Faculdade de Educação, Universidade Federal de Juiz de Fora, Juiz de Fora, 2005.

AMORIM, D. M. A participação dos conselhos de educaşão nas politicas públicas dos municípios: um estudo a partir de experiências do conselho municipal de educação de Uberlândia. 2005. 126 f. Dissertação (Mestrado em Educação)-Faculdade de Educação, Universidade Federal de Uberlândia, Uberlândia, 2005.

BRASIL. Constituição (1988). Constituição da República Federativa do Brasil. Diário Oficial da República Federativa do Brasil, Brasília, DF, 05 out. 1988.

BRASIL. Ministério da Educação. Lei no 5.692, de 11 de agosto de 1971. Fixa diretrizes e bases para o ensino de $1^{\circ}$ e $2^{\circ}$ graus, e dá outras providências. Diário Oficial [da] República Federativa do Brasil, Brasília, 12 ago. 1971.

BRASIL. Ministério da Educação. Lei no 9.394, de 20 de dezembro de 1996. Estabelece as Diretrizes e Bases da Educação Nacional. Diário Oficial da República Federativa do Brasil, Brasília, DF, 23 dez. 1996.

BRASIL. Ministério da Educação. Lei no 9.131, de 24 de novembro de 1995. Altera dispositivos da Lei $\mathrm{n}^{\circ}$ 4.024, de 20 de dezembro de 1961, e dá outras providências. Diário Oficial da República Federativa do Brasil, Brasília, DF, 25 nov. 1995.

BRASIL. Ministério da Educação. Programa Nacional de Capacitação de Conselheiros Municipais. Brasília: MEC, 2004. Caderno de Referência.

BRASIL. Ministério da Educação. Perfil dos Conselhos Municipais de Educação - 2007. Brasília: MEC, 2008.

CURY, C. R. J. Conselhos de educação: fundamentos e funções. Revista Brasileira de Politica e Administração da Educação, Porto Alegre, n. 22, p. 41-67, jan./jun. 2006.

INSTITUTO BRASILEIRO DE GEOGRAFIA E ESTATÍSTICA - IBGE. Pesquisa de informacões básicas municipais: perfil dos Municípios Brasileiros. Brasília: IBGE, 2009. Disponível em: < http://www.ibge.gov.br/home/estatistica/economia/perfilmunic/2009/ default.shtm>. Acesso em: 20 nov. 2011.

INSTITUTO NACIONAL DE ESTUDOS E PESQUISAS EDUCACIONAIS - INEP. Microdados do Censo Escolar - 2010. Brasília: INEP, 2011. Disponível em: < http://portal. inep.gov.br/basica-censo >. Acesso em: 10 maio 2012.

LIMA, A. B.; NUNES, J. C. Conselho municipal de educação e controle social. In: LIMA, A. B. (Org.). Estado e controle social no Brasil. Uberlândia: Ed. UFU, 2011. p. 103-121. 
MAROY, C. Régulation des systèmes éducatives. In: VAN ZANTEM, A. Dictionaire de l' éducation. Paris: PUF, 2008.

MINAS GERAIS. Conselho Estadual de Educação. Parecer no 500, de 13 de maio de 1998. Informativo Mai de Ensino, Belo Horizonte, n. 269, p. 17-28, 1998.

SARMENTO, D. C. Criação dos Sistemas Municipais de Ensino. Educação \& Sociedade, Campinas, v. 26, n. 93, p. 1362-1390, 2005.

SILVEIRA JUNIOR, O. B. O fortalecimento da democracia deliberativa por meio dos conselhos gestores: o caso do conselho municipal de educação do município de Poços de Caldas. 2009. 182 f. Dissertação (Mestrado em Administração das Organizações)-Faculdade de Economia, Administração e Contabilidade de Ribeirão Preto, Universidade de São Paulo, Ribeirão Preto, 2009.

SOUZA, D. B.; VASCONCELOS, M. C. C. Os conselhos municipais de educação no Brasil: um balanço das referências nacionais (1996-2002). Revista Ensaio, Rio de Janeiro, v. 14, n. 50, p. 39-56, 2006.

SOUZA, D. B.; VASCONCELOS, M. C. C. CMEs no Estado do Rio de Janeiro: considerações sobre o funcionamento institucional e sociopolítico a partir de 28 de suas localidades. In: VALLE, B. B. R.; VASCONCELOS, M. C. C. (Orgs.). Conselhos Municipais de Educação: organização e atribuições nos Sistemas de Ensino do Estado do Rio de Janeiro. Rio de Janeiro: Faperj/Quartet, 2012. p. 29-62.

TEIXEIRA, L. H. G. Conselhos municipais de educação: autonomia e democratização do ensino. Caderno de Pesquisa, São Paulo, v. 34, n. 123, p. 691-708, set./dez. 2004. http:/ / dx.doi.org/10.1590/S0100-15742004000300009

TELES, R. M. Conselho municipal de educação: a participação da sociedade civil na gestão do direito à educação. 2003. 222 f. Dissertação (Mestrado em Educação)-Faculdade de Educação, Universidade Federal de Minas Gerais, Belo Horizonte, 2003.

WERLE, F. O. C.; THUM, A. B.; ANDRADE, A. C. O Sistema Municipal de Ensino e suas implicações para a atuação do Conselho Municipal de Educação. Revista Brasileira de Política e Administração da Educação, Porto Alegre, v. 24, n. 1, p. 79-109, jan./abr. 2008. WERLE, F. O. C. Gestão da educação municipal: composição dos Conselhos Municipais de Educação do Rio Grande do Sul. Revista Ensaio, Rio de Janeiro, v. 14, n. 52, p. 349-364, set. 2006. WERLE, F. O. C. CME como política estruturadora do campo da educação no município. In: SOUZA, D. B. Conselhos municipais e controle social da educação: descentralização, participação e cidadania. São Paulo: Xamã, 2008. p. 211-23.

\section{NOTAS}

${ }^{1}$ Embora não tenha sido viabilizada, essa terceira alternativa apontada pelo CEE/MG ainda em 1998 aproxima-se dos princípios debatidos pela Conferência Nacional de Educação (Conae) realizada em 2010, cuja temática foi: Construindo o Sistema Nacional Articulado: o Plano Nacional de Educação, Diretrizes e Estratégias de Ação.

${ }^{2}$ Para uma análise sobre a produção acadêmica a respeito dos CMEs no Brasil, ver Souza e Vasconcelos (2006). 
${ }^{3}$ Estudos semelhantes referindo-se ao Rio Grande do Sul e ao Rio de Janeiro podem ser encontrados, respectivamente, em Werle, Thum e Andrade (2008) e Souza e Vasconcelos (2012).

${ }^{4}$ Werle $(2006,2008)$ analisa os atos legislativos de criação de CMEs no Rio Grande do Sul, aprofundando-se sobre as características desses conselhos por meio da análise da legislação de 80 municípios.

5 Considera-se que "as experiências de democracia participativa têm revelado que, na maioria das vezes, há mais racionalidade e melhores resultados na gestão pública quando a população pode decidir ou, ao menos, opinar e fiscalizar” (BRASIL, 2004, p. 4).

6 “Artigo 31. A fiscalização do Município será exercida pelo Poder Legislativo Municipal, mediante controle externo, e pelos sistemas de controle interno do Poder Executivo Municipal, na forma da lei. $\int 1^{\circ}$ - O controle externo da Câmara Municipal será exercido com o auxílio dos Tribunais de Contas dos Estados ou do Município ou dos Conselhos ou Tribunais de Contas dos Municípios, onde houver" (BRASIL, 1988).

Recebido: $14 / 08 / 2012$

Aprovado: 01/11/2012

Contato: Universidade Federal de Minas Gerais Faculdade de Educação Av. Antonio Carlos, 6.627, Pampulha CEP $31270-901$ Belo Horizonte, MG Brasil 